Article

\title{
Comparative Numerical Analysis on Vertical Wind Turbine Rotor Pattern of Bach and Benesh Type
}

\author{
Fanel Dorel Scheaua
}

MECMET Research Center, Dunarea de Jos University of Galati, 800008 Galati, Romania; fanel.scheaual@ugal.ro; Tel.: +40749843765

Received: 19 March 2020; Accepted: 30 April 2020; Published: 6 May 2020

check for updates

\begin{abstract}
In this work, 3D models in classic configuration of Bach and Benesh rotor type, as well as models with modified blade pattern geometry were analyzed from the air circulation point of view inside the rotor enclosure in order to identify the operating parameters differences according to rotor geometric modified configuration. Constructive design aspects are presented, as well as results obtained from the virtual model analysis in terms of circulation velocity and pressure values which enhance rotor operation related to torque and power coefficients. The rotors design pattern is made according to previous results obtained by different researchers who have performed numerical analysis on virtual models and tests on the experimental rotor models using the wind tunnel. The constructive solutions are describing two-bladed rotor models, in four new designed constructive variants and analyzed using ANSYS CFX. The air velocity specific values, static and total pressure recorded at the rotor blade level are highlighted, that influence the obtaining of rotor shaft torque and power. Also torque coefficient (CT) and power coefficient (CP) values according with specific values of tip speed ratio (TSR) are presented for each analyzed case. The analysis results show higher power coefficient values for analyzed Bach V2 and Benesh V2 rotor modified models compared to the classic Bach and Benesh models for 0.3 TSR of 0.11-012 CP, 0.4 TSR of $0.18 \mathrm{CP}$ (Benesh V2 model) and 0.27 CP at 0.6 TSR (Bach V2). The resulted values confirm that Benesh V2 model offers higher CP up to $5 \%$ at TSR $0.3,2 \%$ at TSR 0.6 and 3\% at TSR 0.4 compared to the Benesh classical model. The Bach V2 model offers $4 \%$ higher CP compared to the classic Bach model at TSR 0.6. Based on these results it is intended the further analytical and experimental research in order to obtain optimal rotor pattern.
\end{abstract}

Keywords: wind action; air flow; wind turbine; rotor; Bach type; Benesh type; 3D modeling; CFD

\section{Introduction}

The force generated by the atmospheric air masses movement represent a considerable resource that currently is still underused at the global level in order to obtain energy.

In time, multiple solutions have been developed that can capture the wind force and turn it into mechanical rotational energy at the axis of a rotor.

From the constructive point of view, the main wind turbine types can be differentiated by the manner in which the rotor is positioned with the rotation axis in a horizontal direction defining the horizontal axis wind turbines (HAWT) or in vertical direction describing the vertical axis wind turbines (VAWT).

In 1931, the Finnish engineer Siguard Savonius presented in detail the model of S-shaped in section view turbine rotor propeller, as a vertical axis rotor considered to be driven by drag forces (Abraham et al. 2012) and the operating performance of the rotor is influenced by the constructive geometrical conditions but also by the air circulation parameters [1]. 
The Savonius turbine rotor has many advantages over simple construction and low cost. The operation of the Savonius type rotor is independent of the wind direction, benefiting from easy starting with good torque values even at low wind velocities.

The initial model proposed by Savonius has been analyzed and tested by many researchers over time being continually modified in order to obtain higher power performances.

Forwards are briefly presented some of the research initiatives carried out in the last period aimed at the constructive and functional optimization of the Savonius rotor model.

The aspects considered for obtaining an optimum rotor model are related to the number of blades, but also to the blade shape and arrangement within the rotor enclosure.

For the rotor, different numbers of the blades starting from 2 to $3,4,5$ and even more blades were considered, in radial arrangement, being performed numerical analyzes and experimental tests using the wind tunnel.

Specific operating values or specific parameters are represented by the power coefficient and torque at the rotor shaft.

For the design stage of the rotor CAD modeling methods were used and the resulting models were introduced in the CFD analysis realized with specialized programs in the dynamic regime considering the air flow inside and outside the rotor enclosure. The obtained results were adopted as the starting points in the construction of the rotor physical model that will be tested experimentally through the wind tunnel. The validation of the results obtained from the CFD analyzes on a virtual model is performed based on the experimental data and the cycle of defining the constructive solution of the rotor is completed.

Due to the fact that the wind action determines the blade rotational motion but at the same time it tends to brake the other blade and produce a negative value couple, Altan et al. (2008) propose a constructive solution that involves the use of a curtain near the enclosure of the conventional Savonius rotor, which has the role of directing the air flow-rate to the active shovel that takes over the entire air flow. There have been performed experiments and numerical analyzes of the rotor without curtain and with curtain. The results show that the curtain rotor performs better than the simple model recording up to $38.5 \%$ higher power coefficient values than the conventional rotor model [2].

The power coefficient values obtained by Savonius rotor type is usually in the range of $0.05-0.3$ according to Akwa et al. (2012) [3].

Regarding the rotor model design parameters, Mahmoud et al. (2012) studied different geometries of the Savonius turbine rotor in the classical section, Bach-type and elliptical, in order to determine the optimum rotor operating efficiency parameters for 2, 3 or 4 blades having an end plate at each rotor end [4]. Analyzes were performed for the rotor with end plate but also without end plate. The results obtained show that a two-bladed rotor with mounted base plate has a higher efficiency compared to the other studied models. The results were obtained from CFD analysis on 2D models, being compared with the experimental data obtained on the physical model tested in the wind tunnel.

Jeon et al. obtained results of a significant power coefficient increase with up to $36 \%$ compared to the rotor models without end plates, being emphasized the linear dependence of the power coefficient in relation to the end plates area [5].

Kacprzak et al. (2013) conducted the study on the performance of the Savonius turbine rotor on a classic, Bach type and elliptical rotor model of the rotor by applying a laminar-turbulent transition model regarding the air flow rate at the rotor enclosure at different TSR values [6]. The obtained results are presented as values of power coefficient and torque at the rotor shaft, as well as the torque values depending on the blade incidence angle.

Wind velocity is a key parameter in obtaining the optimum operating values of the Savonius rotor type. The experiments performed by Morshed et al. (2013) on the virtual and experimental model in the wind tunnel aimed to obtain the operational performance values of a 3 blades turbine rotor with different overlap ratios and without overlap. The experiments were performed using low values of air circulation speed but with different values of Reynolds number. The pressure values around 
the concave and convex surfaces for each blade as well as the torque values in static regime were measured. Based on the experimental data, it was possible to calculate the characteristic aerodynamic parameters represented by traction coefficients, static torque coefficients and power coefficients for each model analyzed separately. By comparing the numerical analysis results with the experimental data from 3 different models it was established that there is a significant effect of the overlap ratio and Reynolds number in optimizing the operation of the Savonius turbine rotor. Thus, at Reynolds number high values of the, the turbine model without overlap ratio has better aerodynamic coefficients. At lower Reynolds values, the model with moderate overlap ratio gives better results [7].

A special configuration of the turbine rotor is made by Sanusi et al. (2016) by using a rotor with circular section blades in combination with elliptical concave section blades. The stated purpose is to obtain information regarding the modification of the rotor performance parameters with the change of the initial configuration. The experimental method is used by including the prototype rotor model with 3 different blades types in the wind tunnel. The obtained experimental results show the influences given by the initial rotor configuration modification through different shaped blade models introduced, so that the modified rotor performances are up to $11 \%$ better compared to the conventional rotor in terms of power coefficient at TSR values of 0.79 [8].

Experimental wind tunnel research has also been carried out on innovative models of the 2-blade Savonius rotor for a reduced scale energy conversion unit by Roy et al. (2015). Based on previous experiments on different models of rotor blades, a 2-blade rotor has been developed which is tested to determine the specific terms represented by the power and torque coefficient. Experiments were performed including with semi-circular or semi-elliptical blades (Benesh and Bach type) to be able to compare the experimental results. The dependencies of the static and dynamic characteristics of the Reynolds number are shown and an optimized value of $34.8 \%$ for the power coefficient for the innovative two-bladed turbine rotor is shown by the experimental results obtained [9].

On the same principle of using the blade shape optimization genetic algorithm followed by numerical and experimental conducted work Ramadan et al. (2018) show that for the optimized blade the rotor efficiency is $28 \%$ compared to classical rotor with semi-circular blades [10].

Tian et al. (2018) by numerical analysis of a type of Savonius rotor whose blades are modified presents a procedure aimed at the functional optimization of the rotor. For each geometric blade model, numerical analysis is performed to identify the power coefficient peak values. Thus, a value of $4.41 \%$ higher power coefficient of the optimized model is obtained than the conventional Savonius rotor model [11].

An innovative method of parametric modeling and rotor blade shape optimization has been proposed by Zhang et al. (2017) in order to achieve improved rotor operational results. The method consists of bending a quadratic polynomial curve to obtain the rotor blade. A series of transient CFD analyzes were performed on the virtual model in order to determine the optimum values for the power coefficient according to the geometric model of the rotor blades. Thus, a global model of the blade surface response to the wind action with the Kriging method is obtained, which establishes the relation between the power coefficient and the design parameters of the rotor blade. The optimum blade design parameters can be determined with particle swarm optimization (PSO) depending on the surface response to the external wind demands. Thus, the optimum blade geometrical model was obtained as a hook-section whose performance shows a power coefficient increased by $6 \%$ compared to the conventional Savonius model [12].

Some of the research initiatives in the field of vertical axis wind turbine rotor (Savonius type) were presented, with emphasis on the modified Bach and Benesh type models which obtained improved results compared to the classic Savonius model in terms of torque and power coefficient.

Starting from the modified concept of the Bach and Savonius rotor type, 3D models had been constructed with specific blades geometry which are analyzed using Ansys CFX in order to identify the best torque and power coefficient specific values for tip speed ratio values ranged from 0.1 to 0.7 . 
The study is based on numerical analysis on three-dimensional model for multiple rotor patterns: Classic Bach, Classic Benesh, Bach with concave blades (Bach V1), Bach with convex blades (Bach V2), Benesh with concave blades (Benesh V1), Benesh with convex blade (Benesh V2).

By constantly external gauge values regarding the height and diameter of all analyzed rotor models, the analysis results establish the theoretical possibilities of obtaining the maximum power coefficient according to tip speed ratio (TSR) values from analyzed model separately, thus being able to choose the optimal variant for the construction of an experimental model.

\section{Main Performance Parameters of the SAVONIUS Type Rotor}

Savonius type vertical axis wind turbines have the ability to take the wind force in the form of kinetic energy and convert it into mechanical axis rotation energy. The construction of a Savonius turbine rotor in the classic version with end plates and blade gap is shown schematically in Figure 1.
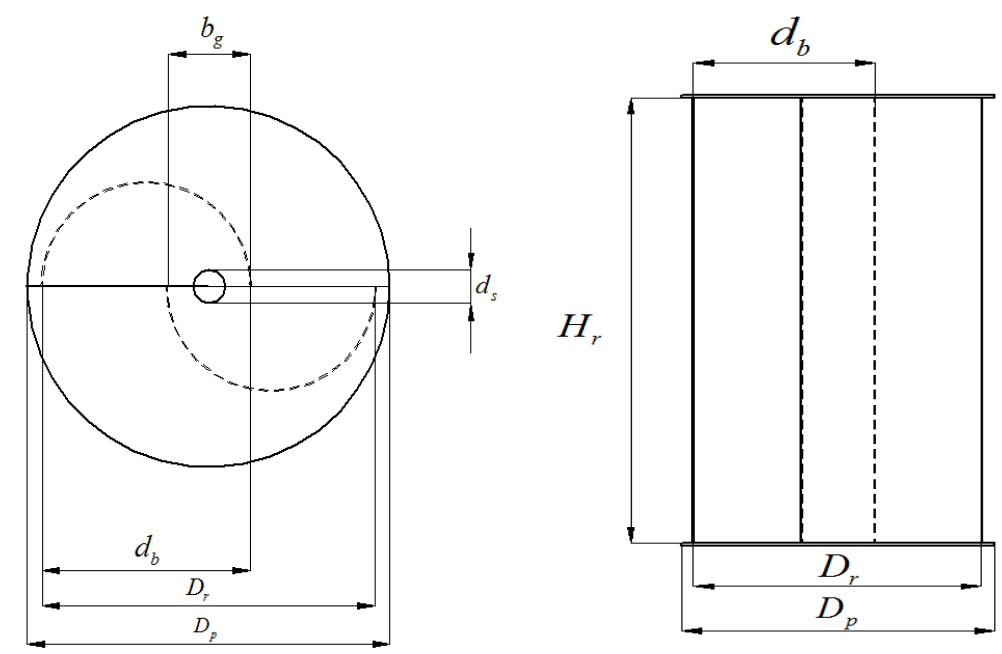

Figure 1. Design elements of the Savonius classic rotor.

The main parameters involved in the construction and operation of the Savonius type rotor are represented by the basic geometric parameters that describe the diameter of the rotor and blades, the radial and angular positioning of the blades, as well as the constructive height of the rotor, the functional parameters resulting from the operation of the rotor represented by the torque developed at the shaft, the power coefficient, the torque coefficient, the total power developed.

The basic constructive and functional parameters of the Savonius type turbine rotor can be grouped and presented together with the characteristic relations (Table 1).

Table 1. Basic constructive and functional parameters of the Savonius turbine rotor.

\begin{tabular}{cc}
\hline \multicolumn{2}{c}{ Constructive Design and Functional Parameters } \\
\hline Rotor diameter $\left(D_{r}\right)$ & Total wind power: $N_{W}=\frac{1}{2} \rho_{a} A_{r} v^{3}$ \\
\hline Rotor height $\left(H_{r}\right)$ & Angular velocity: $\omega_{r}=\frac{1}{30} \pi n$ \\
\hline Rotor area: $A_{r}=D_{r} \cdot H_{r}$ & Tip speed ratio (TSR): $\lambda=\frac{1}{2} \frac{\omega \cdot D_{r}}{v}$ \\
\hline End plate diameter $\left(D_{p}\right)$ & Rotor torque $\left(T_{r}\right)$ \\
\hline Shaft diameter $\left(d_{s}\right)$ & Pressure coefficient: $C_{p}=\frac{2\left(p-p_{a}\right)}{\rho_{a} v^{2}}$ \\
\hline Blade diameter $\left(d_{b}\right)$ & Torque coefficient: $C T=\frac{4 T_{r}}{\rho_{a} v^{2} D_{r} H_{r}}$ \\
\hline Blade gap $\left(b_{g}\right)$ & \\
\hline Aspect ratio: $a=\frac{H_{r}}{D_{r}}$ & Power coefficient: $C P=\frac{2 T \omega}{\rho_{a} v^{3} D_{r} H_{r}}$ \\
\hline Overlap ratio: $\beta=\frac{b_{g}}{d_{s}}$ & \\
\hline
\end{tabular}




\section{Specific Design Elements for the Rotor Blades Profile and Constructive Types}

There are presented different models that have been proposed by different researchers from around the world in order to improve the performance of the initial rotor variant proposed by Savonius. Innovative models were designed based on blade profile geometry curve modification. Are presented the main blades profile models that have been proposed, analyzed and tested experimentally, giving better operating results.

The blade profile proposed by Bach replaces the blade circular profile with a straight line consisting of a straight line and an end arc. The Bach profile, shown in Figure 2a, was tested in the wind tunnel and the results show better performances compared to the traditional Savonius model for both low and high TSR values. But for the middle TSR values the Savonius rotor is more efficient in terms of power coefficient than the Bach model which has maximum values of the power coefficient at $\operatorname{TSR}=0.9[1,2,11,13,14]$.

Comparative analyzes between the conventional Savonius rotor model and the Bach model were also performed by Ushiyama et al. to determine the optimal model [14,15].

It was observed that the gap ratio value influences the rotor efficiency parameters on the Bach model. Thus, for values up to 0.3 for the gap ratio, the maximum power coefficient of 0.23 is obtained, $9 \%$ higher than the conventional model with semicircular profile of the blade. Similar results were obtained also by Modi and Fernando from the experiments carried out on the Bach model, the experimental results showing that the gap ratio values close to the zero value guarantee the higher values of the power coefficient $[14,16]$.

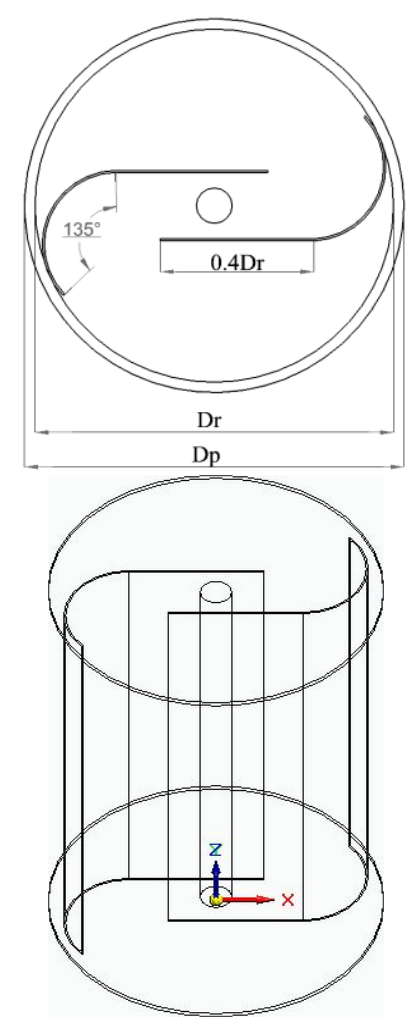

(a)

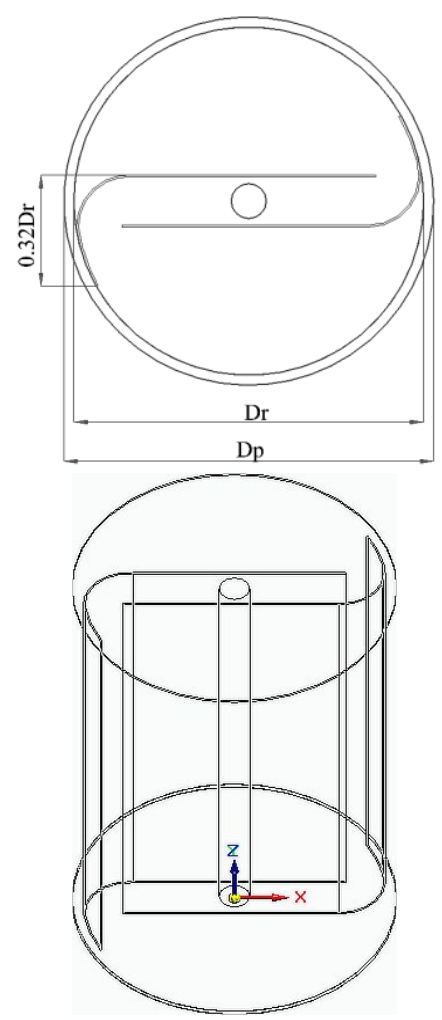

(b)

Figure 2. Schematically representation of Bach and Benesh rotor profile. (a) Bach-type rotor model [14]; (b) Benesh blade profile [17].

Regarding the parameters of the blade profile to the Bach model numerical analyzes performed by Sukanta Roy et al. were directed to the study of the influence of the values of the angle of the arc of the blade for values between 90 and 165 degrees and TRS in the range 0.2 to 1.4 . [9,14]. The results 
show that the improved values for the power coefficient are obtained for higher values of the blade arc angle due to the higher values of the positive moment obtained. The maximum values for the blade arc angle are obtained at valuesup to 135 degrees, and the maximum value for the power coefficient is 0.34 at the TSR of 0.8 .

Another constructive variant for the rotor model starting from the Bach model is represented by Benesh model (Figure 2b), who presents a 1996 patented model whose blade geometry has an end arc connected to a straight line.

Using a combination of different beam profiles that are assembled together, Sivasegaram proposes a profile model for the turbine rotor that has been tested and the results show better values for the power coefficient than the semi-circular blade profile $[14,18,19]$.

The profile shown in Figure 3 allows obtaining a power coefficient of 0.2.

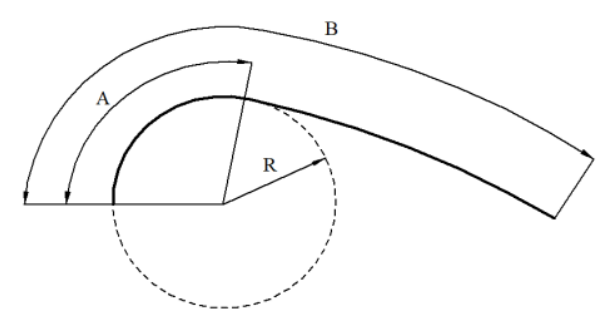

Figure 3. Sivasegaram blade model [18].

In 2015 Roy and Saha tested the Benesh model along with the improved Bach model, the elliptical model and the traditional Savonius model in the wind tunnel. The experimental results show values presented in Table 2 [9].

Table 2. Experimental results for tested rotor models [9].

\begin{tabular}{cc}
\hline Rotor Model & Power Coefficient \\
\hline Benesh & 0.29 \\
Bach improved & 0.3 \\
Semicircle & 0.26 \\
Elliptical & 0.23 \\
\hline
\end{tabular}

According with the result values from the experimental work accomplished on two rotor models can be made a comparison between two rotor constructive types in order to highlight the optimal results in terms of power coefficient (Cp) function of tip speed ratio (TSR) as presented in Figure 4 diagram.

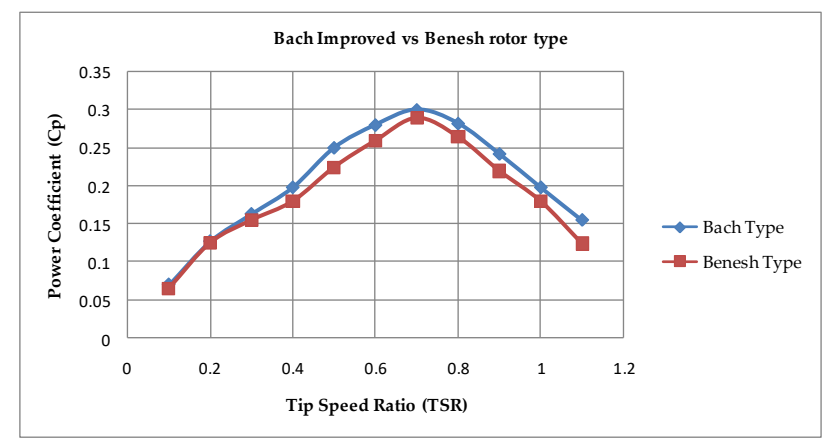

Figure 4. Experimental results for power coefficient $(\mathrm{Cp})$ function of tip speed ratio (TSR) for Bach and Benesh rotor models.

Experimental research has determined that by using the Benesh model for the rotor, the possibilities of starting the rotor can be improved with the reduction of the static torque coefficient compared to 
the other models tested and power coefficient recorded above the values recorded by the conventional Savonius model $[9,17]$.

Experimental researches also performed by Rahai and Hefazi on 2-blade rotor model with and without spanwise for values of zero and 0.48 for the Savonius and Benesh models.

The results show that both profiles used in the experiment have maximum power coefficient at TSR values in the range 0.8-1.2. The maximum power coefficient is registered by the Benesh profile of 0.31 , while the conventional Savonius profile has registered $0.27[17,20]$.

From the research done so far, it follows that the Bach model presents the best results in terms of performance with a power coefficient of 0.34 , but also the Benesh model provide good performance values [14].

\section{Modeling Elements for Constructive and Functional Optimization of the Rotor Model Pattern}

Multiple constructive versions of the Savonius type rotor were analyzed. The results show that some constructive variants like Bach and Benesh models are providing the best values regarding the performance coefficients.

Starting from the two rotor constructive types, 3D assembly models having the main dimensions of $1000 \mathrm{~mm}$ height, $700 \mathrm{~mm}$ diameter, $70 \mathrm{~mm}$ shaft diameter and 1.428 aspect ratio for the rotor were built with specific blade geometry that were introduced in the CFD analysis with Ansys CFX in order to determine the performance characteristics based on the numerical analysis method for both Bach and Benesh constructive types [14,17,21-24].

The analysis is performed as air flow simulation through the rotor enclosure in order to be able to identify the flow regime within rotor blades region at certain input velocity values and further to obtain the specific velocity and pressure values but also rotor shaft torque and provided power values for each analyzed rotor constructive variant case.

Through the performed analysis and obtained results it is desired to identify the optimal constructive variant of rotor type that can provide highest performance parameters in operation.

Starting from the basic geometrical elements of Bach and Benesh models, different geometrical models were developed for the turbine rotor blade section [25-27].

For each basic model, for both Bach and Benesh types, two new models have been designed that present concave and convex geometry of the blade section.

The schematic representation of the design elements used as well as the geometric dimensions of each model is presented in Figure 5, highlighting the models considered for numerical analysis on a three-dimensional virtual model.

The blade gap and overlap ratio values are presented for each rotor model separately in Table 3. Geometric dimensions with respect to the rotor diameter and height are maintained at the same values for all rotor constructive types except the blade constructive form which is different for each rotor type [28-30].

Table 3. Blade gap and overlap ratio for main rotor types considered for analysis.

\begin{tabular}{ccc}
\hline & Main Rotor Patterns & \\
\hline Bach & Bach V1 & Bach V2 \\
\hline Blade gap: $b_{g}=132 \mathrm{~mm}$ & Blade gap: $b_{g}=102.42 \mathrm{~mm}$ & Blade gap: $b_{g}=182.32 \mathrm{~mm}$ \\
\hline Overlap ratio: $\beta=1.88$ & Overlap ratio: $\beta=1.46$ & Overlap ratio: $\beta=2.6$ \\
\hline Benesh & Benesh V1 & Benesh V2 \\
\hline Blade gap: $b_{g}=97 \mathrm{~mm}$ & Blade gap: $b_{g}=87.5 \mathrm{~mm}$ & Blade gap: $b_{g}=157.37 \mathrm{~mm}$ \\
\hline Overlap ratio: $\beta=1.38$ & Overlap ratio: $\beta=1.25$ & Overlap ratio: $\beta=2.24$ \\
\hline
\end{tabular}




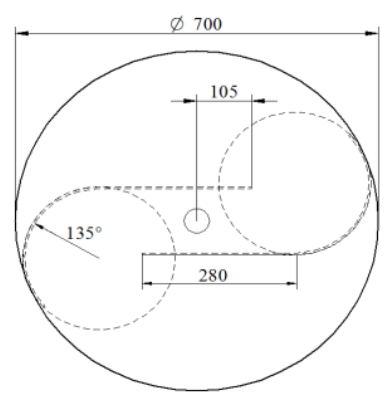

(a) Bach type model

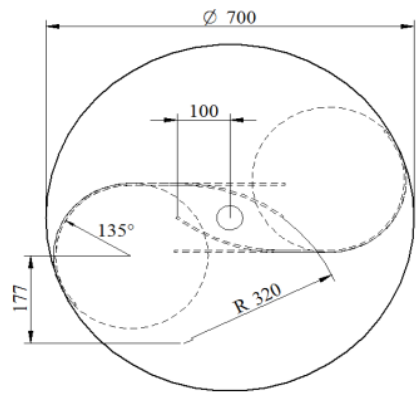

(c) Bach type modified model-V1

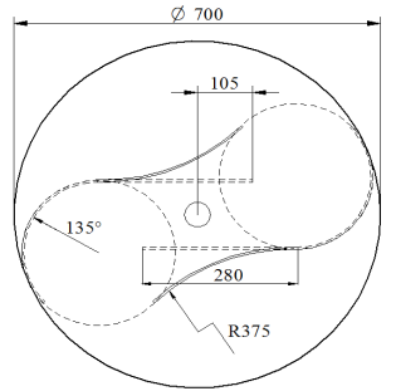

(e) Bach modified model-V2

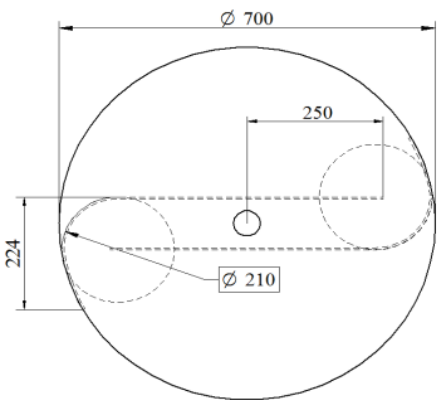

(b) Benesh type model

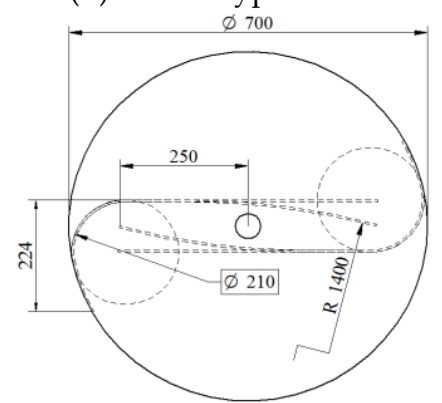

(d) Benesh type modified model-V1

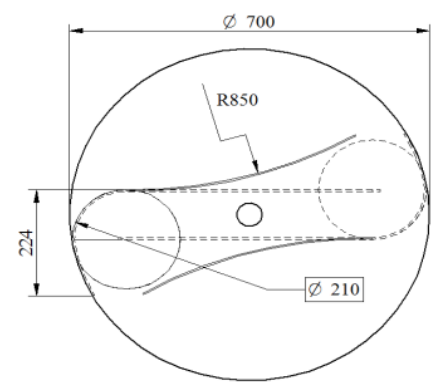

(f) Benesh modified model-V2

Figure 5. Main rotor model types considered for numerical analysis (dimensions in $\mathrm{mm}$ ).

\section{Simulation Elements for Turbine Rotor Model Pattern}

For the constructive solutions presented schematically in Table 3, overall 3D models were created which were introduced in the CFD analysis with Ansys CFX.

Numerical analysis of air flow within the fluid enclosure containing the rotor consists of numerically solving Navier-Stokes equations for unsteady flow of a fluid around a three-dimensional model [31,32].

The mathematical model contains the equations that define the state of continuity and momentum and can thus be presented as follows [33,34]:

$$
\text { Continuity equation: } \frac{\partial u}{\partial x}+\frac{\partial v}{\partial y}+\frac{\partial \omega}{\partial z}=0
$$

$$
\begin{aligned}
& X-\text { Momentum: } \frac{\partial u}{\partial t}+u \frac{\partial u}{\partial x}+v \frac{\partial u}{\partial y}+\omega \frac{\partial u}{\partial z}=-\frac{\partial p}{\partial x}+\frac{1}{\operatorname{Re}}\left(\frac{\partial^{2} u}{\partial x^{2}}+\frac{\partial^{2} u}{\partial y^{2}}+\frac{\partial^{2} u}{\partial z^{2}}\right) \\
& Y \text {-Momentum: } \frac{\partial v}{\partial t}+u \frac{\partial v}{\partial x}+v \frac{\partial v}{\partial y}+\omega \frac{\partial v}{\partial z}=-\frac{\partial p}{\partial y}+\frac{1}{\operatorname{Re}}\left(\frac{\partial^{2} v}{\partial x^{2}}+\frac{\partial^{2} v}{\partial y^{2}}+\frac{\partial^{2} v}{\partial z^{2}}\right) \\
& Z-\text { Momentum }: \frac{\partial \omega}{\partial t}+u \frac{\partial \omega}{\partial x}+v \frac{\partial \omega}{\partial y}+\omega \frac{\partial \omega}{\partial z}=-\frac{\partial p}{\partial z}+\frac{1}{\operatorname{Re}}\left(\frac{\partial^{2} \omega}{\partial x^{2}}+\frac{\partial^{2} \omega}{\partial y^{2}}+\frac{\partial^{2} \omega}{\partial z^{2}}\right)
\end{aligned}
$$

The fluid model is of k-epsilon type turbulence model being the most analyzed model type used in CFD analysis in order to describe turbulent flow regime $[35,36]$. 
The model contains besides the continuity and moment conservation equations and the differential equations that describe the turbulent effect of kinetic energy production rate $(k)$ and the effect of turbulent kinetic energy dissipation rate (epsilon).

The use of both equations proved to be effective for obtaining optimal results for turbulent fluid flow regimes. The basic equations are presented as follows [33,34]:

$$
\begin{gathered}
\frac{\partial}{\partial x_{j}}\left[\frac{v_{t}}{\sigma_{K}} \frac{\partial k}{\partial x_{j}}\right]+v_{t} \frac{\partial u_{i}}{\partial x_{j}}\left(\frac{\partial u_{i}}{\partial x_{j}}+\frac{\partial u_{i}}{\partial x_{i}}\right)-\varepsilon \approx \frac{D k}{D t} \\
\frac{\partial}{\partial x_{j}}\left[\frac{v_{t}}{\sigma_{\varepsilon}} \frac{\partial \varepsilon}{\partial x_{j}}\right]+C_{1} v_{t} \frac{\varepsilon}{k} \frac{\partial u_{i}}{\partial x_{j}}\left(\frac{\partial u_{i}}{\partial x_{j}}+\frac{\partial u_{i}}{\partial x_{i}}\right)-C_{2} \frac{\varepsilon^{2}}{k} \approx \frac{D \varepsilon}{D t}
\end{gathered}
$$

where the Prandtl numbers $\left(\sigma_{\varepsilon} ; \sigma_{k}\right)$ have the property to make the connection between eddy diffusion of $(k ; \varepsilon)$ to the eddy viscosity values of $\left(\sigma_{k}=\frac{v_{t}}{v_{k}} ; \sigma_{\varepsilon}=\frac{v_{t}}{v_{\varepsilon}}\right)$, while the turbulent kinetic energy production rate being described as $k=\frac{1}{2}\left(\bar{u}^{2}+\bar{v}^{2}+\bar{\omega}^{2}\right)$.

The numerical analysis aims to highlight the turbine rotor main operating parameters analyzed according to the input data characterized mainly by the fluid flow velocity (air at 25 degrees Celsius) with declared values of 7 and $8 \mathrm{~m} / \mathrm{s}$ for each analyzed model.

The fluid range is described by a cubic enclosure outside the rotor with a side of $1100 \mathrm{~mm}$. The analyzed rotor main dimensions are represented by the diameter of $700 \mathrm{~mm}$ and a height of $1000 \mathrm{~mm}$, with different blades configuration for each analyzed rotor model.

The analyzed cases are presented in Table 4 together with the initial stated conditions.

\begin{tabular}{|c|c|c|c|c|c|}
\hline \multicolumn{6}{|c|}{ Rotor Model Type } \\
\hline Bach type & Benesh type & Bach V1 & Benesh V1 & Bach V2 & Benesh V2 \\
\hline \multicolumn{6}{|c|}{ Blade Profile } \\
\hline $\begin{array}{l}\text { Straight with } \\
\text { Radius } \\
\text { (R } 140 \mathrm{~mm})\end{array}$ & $\begin{array}{l}\text { Straight with } \\
\text { Radius } \\
\text { (R } 140 \mathrm{~mm} \text { ) }\end{array}$ & $\begin{array}{c}\text { Bent } \\
(\mathrm{R} 320 \mathrm{~mm})\end{array}$ & $\begin{array}{c}\text { Bent } \\
\text { (R } 1400 \mathrm{~mm})\end{array}$ & $\begin{array}{c}\text { Bent } \\
\text { (R 375) }\end{array}$ & $\begin{array}{c}\text { Bent } \\
(\mathrm{R} 850)\end{array}$ \\
\hline
\end{tabular}

Table 4. Main rotor typologies considered for numerical analysis.

The rotor blade configurations are shown in the Figure 6 for each rotor model type.

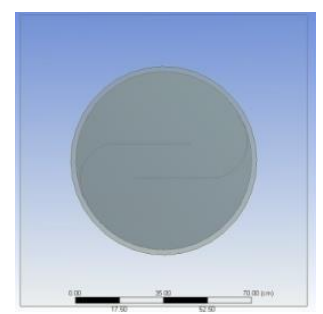

(a) Bach Type

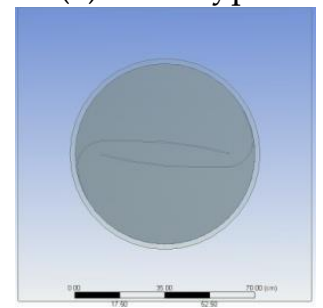

(d) Benesh V1

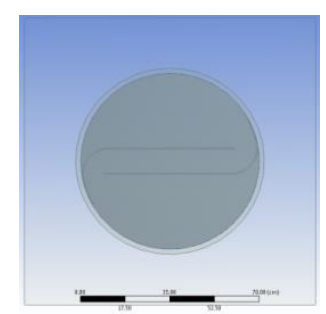

(b) Benesh Type

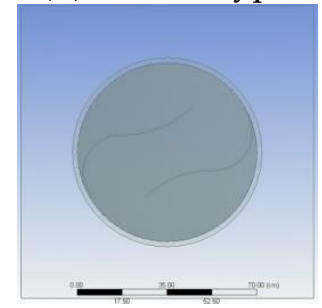

(e) Bach V2

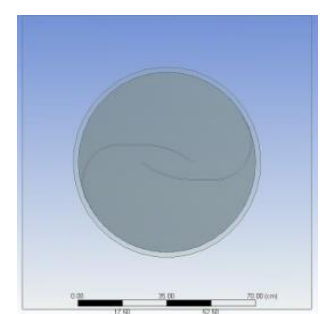

(c) Bach V1

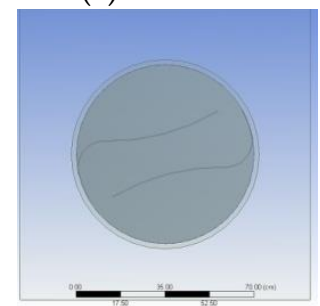

(f) Benesh V2

Figure 6. Specific rotor blade section configuration models considered for analysis. 
The fluid domain (Figure $7 b$ ) containing the rotor was declared as a stationary air volume, at the reference pressure of $1 \mathrm{~atm}$. There were declared air inlet velocity values within the fluid domain with values of 7 and $8 \mathrm{~m} / \mathrm{s}$ respectively.

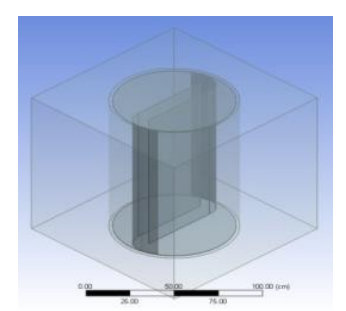

(a) Rotor domain model

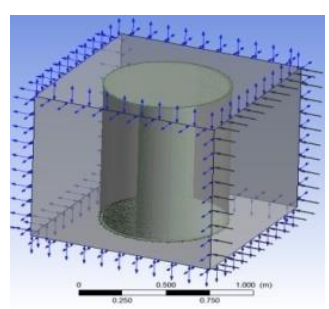

(b) Fluid domain model

Figure 7. Main analysis domains.

For the rotor domain (Figure 7a), rotational motion in relation to z-axis coordinates was adopted. The analysis performed was of a transient blade row type with an option for time period as passing period on the fluid field with the declared value for $1 \mathrm{~s}$, the number of time steps per period of 10-time steps per period, time duration with option for number of single period per run.

The mesh network was created for each model using the tetrahedron method type, mesh sizing on curvature, medium smoothing and curvature normal angle of 20 degrees, minimum size of $1 \mathrm{~mm}$, maximum size of $30 \mathrm{~mm}$. Information about the mesh network for each model is provided in Table 5 .

Table 5. Main rotor model types considered for numerical analysis (dimensions in $\mathrm{mm}$ ).

\begin{tabular}{cccccc}
\hline \multicolumn{7}{c}{ Rotor Model Type } \\
\hline Bach type & Benesh type & Bach V1 & Benesh V1 & Bach V2 & Benesh V2 \\
\hline \multicolumn{7}{c}{ Mesh Network Nodes } \\
\hline 100,449 & 101,696 & 101,581 & 101,599 & 102,094 & 104,383 \\
\hline 458,883 & 462,950 & $4,555,196$ & 463,537 & 458,124 & 461,596 \\
\hline
\end{tabular}

Specific values of air velocity are expected in the fluid area containing the rotor as well as increases in the pressure values at the rotor blades that can provide torque values at the rotor shaft required to ensure rotational motion and obtain the necessary power values.

\section{Results}

Following the CFD analysis, the specific results are obtained which are presented in terms of air circulation velocity and pressure at the rotor level for each analyzed case separately. Also, the numerical results obtained for torque $(\mathrm{CT})$ and power coefficient $(\mathrm{CP})$ recorded for each analyzed model are obtained depending on different tip speed ratio (TSR) values.

The results in terms of air velocity and pressure values distribution are presented in Figure 8.

The results obtained for air velocity and pressure at the level of the analyzed fluid region containing the rotor show the current path-lines formed on the main flow direction from the inlet to the exit area, having changes within the rotor region, depending on the geometrical configuration of the blades.

Higher values of air velocity circulation are recorded on the blade outer area towards the exit, while inside the rotor inner area in the blades vicinity the velocity is in lower values due to the air layers generated stress that meet the rotor blades.

In contrast, the pressure values are higher on the areas in the immediate blade's vicinity where direct pressure action on the blades is recorded by means of hydrostatic forces providing the torque on the rotor shaft. 
The region behind the rotor blades is characterized by low pressure values that allow rotation motion conditions occurrence of rotor.
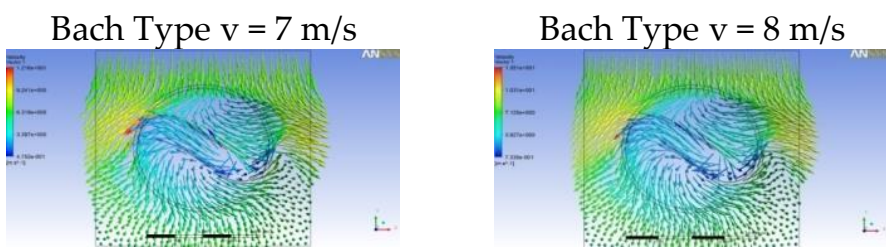

(a) air velocity step 1
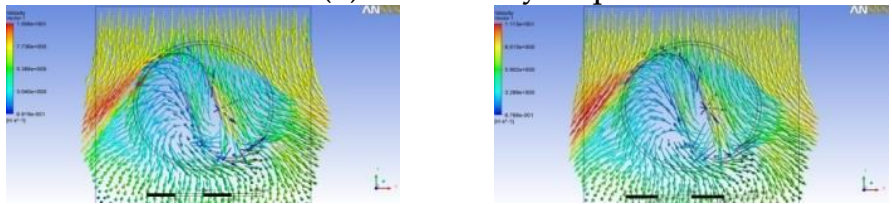

(b) air velocity step 2
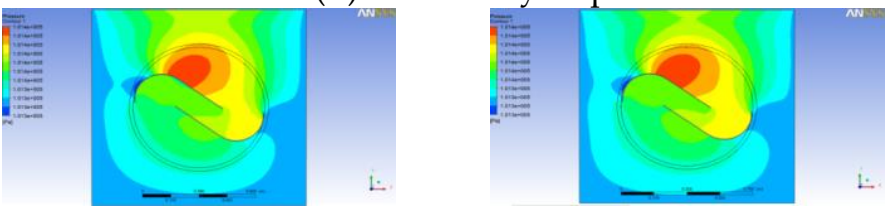

(c) pressure values
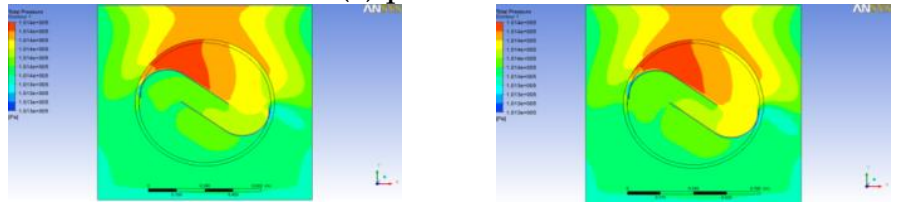

(d) total pressure values

Benesh Type $\mathrm{v}=7 \mathrm{~m} / \mathrm{s}$

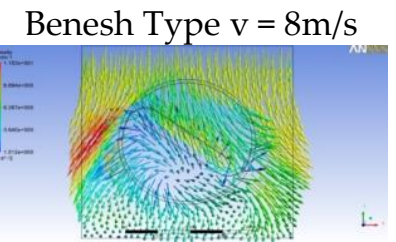

(e) air velocity step 1
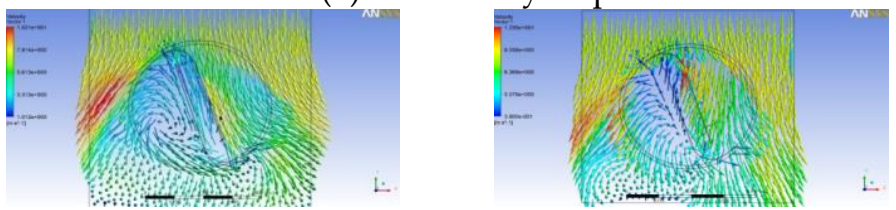

(f) air velocity step 2
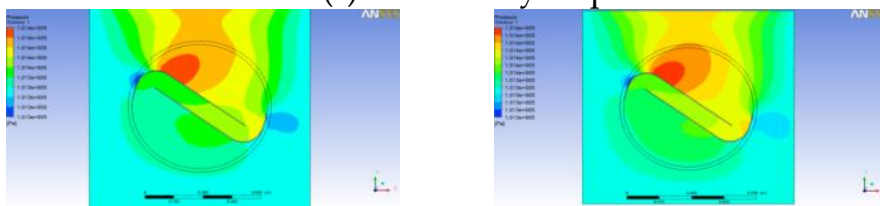

(g) pressure values
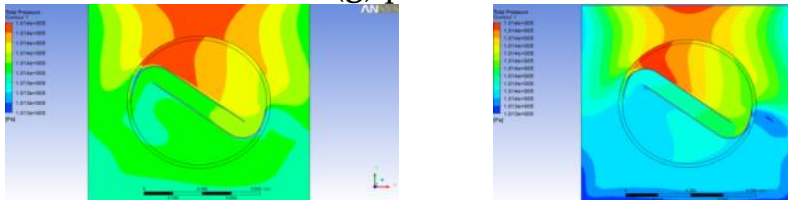

(h) total pressure values

Bach V1 v $=7 \mathrm{~m} / \mathrm{s}$

Bach V1 v $=8 \mathrm{~m} / \mathrm{s}$

Figure 8. Cont. 

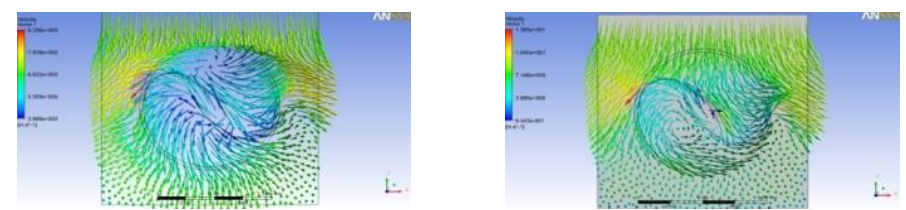

(i) air velocity step 1
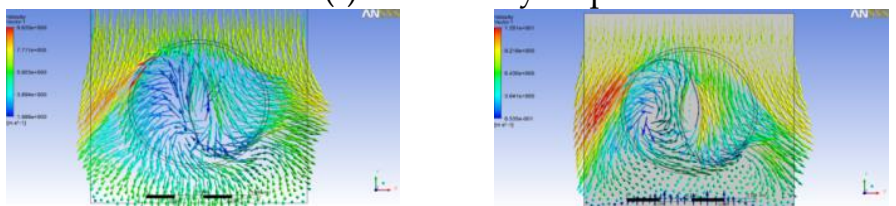

(j) air velocity step 2
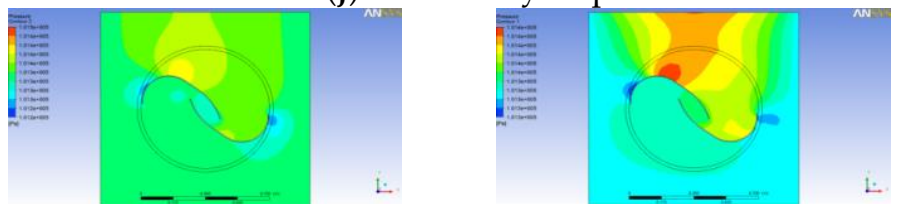

(k) pressure values

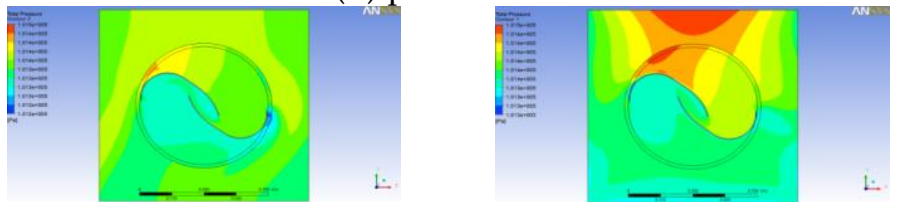

(1) total pressure values
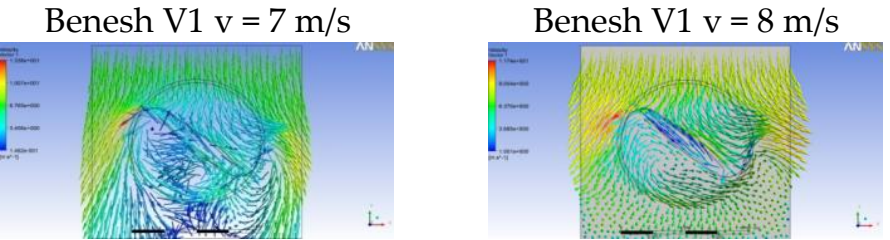

(m) air velocity step 1
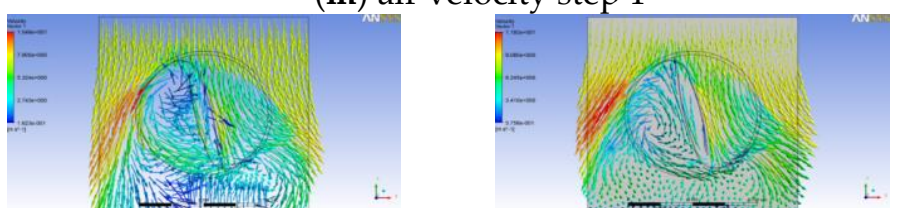

(n) air velocity step 2
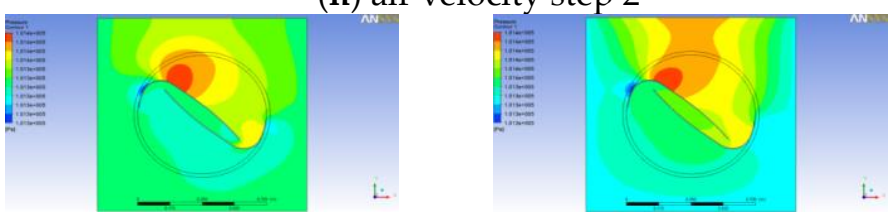

(o) pressure values

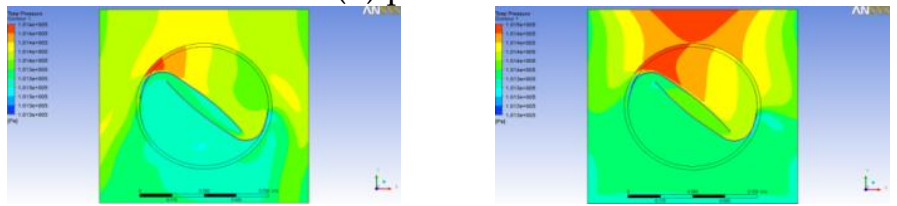

(p) total pressure values

Bach V2 v $=7 \mathrm{~m} / \mathrm{s}$
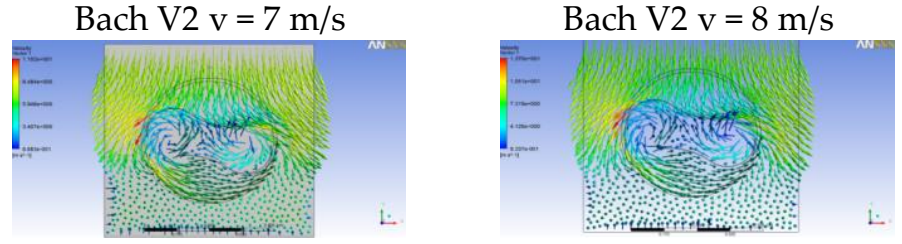

(q) air velocity step 1

Figure 8. Cont. 

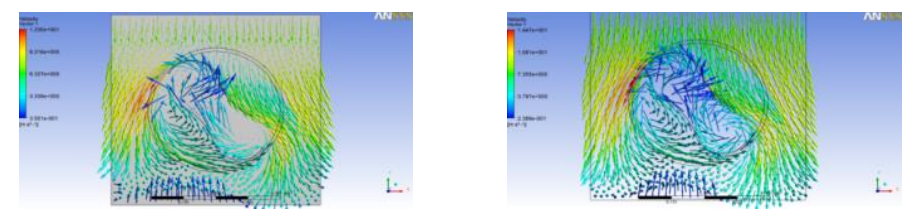

(r) air velocity step 2
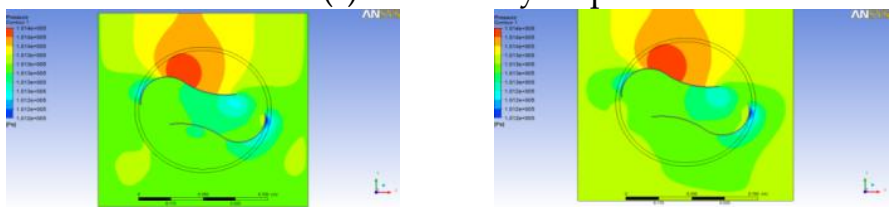

(s) pressure values
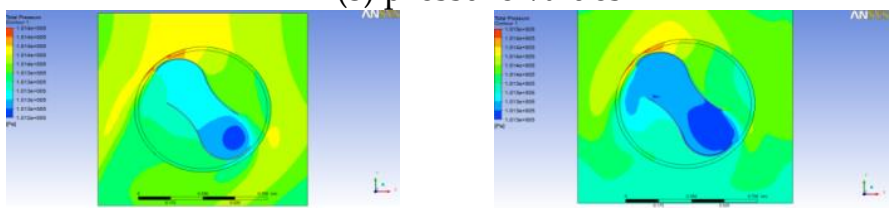

(t) total pressure values
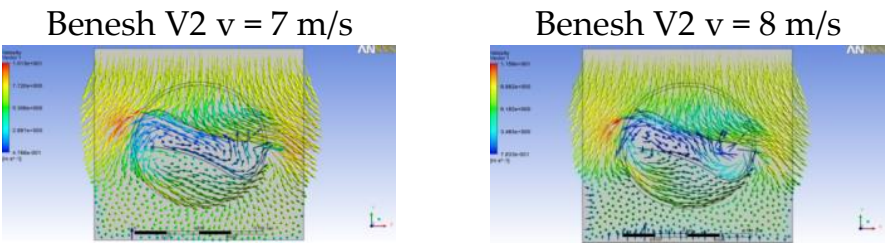

(u) air velocity step 1
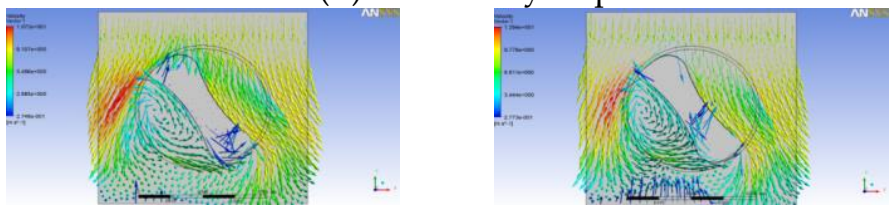

(v) air velocity step 2
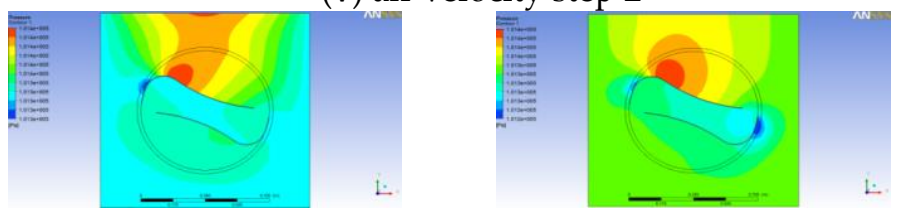

(w) pressure values

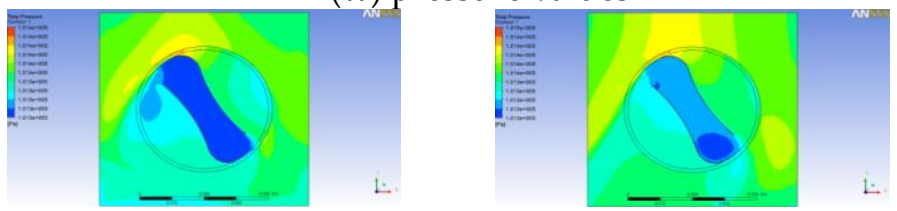

(x) total pressure values

Figure 8. Air velocity and pressure value results for all analyzed cases.

The specific air velocity and pressure values recorded for each analyzed rotor model with different blade geometry configuration are presented in Table 6 . 
Table 6. Velocity and pressure result values for analyzed rotor model types.

\begin{tabular}{|c|c|c|c|c|c|}
\hline \multicolumn{6}{|c|}{ Rotor Model Type } \\
\hline Bach type & Benesh type & Bach V1 & Benesh V1 & Bach V2 & Benesh V2 \\
\hline \multicolumn{6}{|c|}{ Air velocity Values (m/s) } \\
\hline $3.4-8.5$ & $5.6-9.3$ & $3.89-9.21$ & $3.45-9$ & $3.33-10.91$ & $5.49-9.7$ \\
\hline \multicolumn{6}{|c|}{ Pressure Values $(\mathbf{P a})$} \\
\hline 101,400 & 101,400 & $101,300-101,400$ & $101,300-101,400$ & $101,200-101,400$ & $101,400-101,300$ \\
\hline \multicolumn{6}{|c|}{ Reynolds Number } \\
\hline $1.53 \times 10^{5}$ & $2.52 \times 10^{5}$ & $1.75 \times 10^{5}$ & $1.55 \times 10^{5}$ & $1.50 \times 10^{5}$ & $4.37 \times 10^{5}$ \\
\hline $3.83 \times 10^{5}$ & $4.19 \times 10^{5}$ & $4.15 \times 10^{5}$ & $4.06 \times 10^{5}$ & $4.92 \times 10^{5}$ & $5.01 \times 10^{5}$ \\
\hline
\end{tabular}

Rotor Performance Numerical Results

Based on the analyzes performed on the virtual rotor model with blade different geometric configurations, numerical results were obtained in terms of torque at the rotor axis but also of provided power values. The diagrams for torque coefficient (CT) and power coefficient (CP) for each analyzed rotor model according to tip speed ratio (TSR) are presented. The reference tip speed ratio (TSR) range is between 0.3 and 0.7 for which the main interest values related to power $(\mathrm{CP})$ and torque $(\mathrm{CT})$ coefficients are recorded for all analyzed rotor models (Figures 9 and 10).

The values for the power coefficient (CP) as a function of tip speed ratio (TSR) for the Bach and Benesh models (Figure 9a) show uniformity overall in the field of interest presented with slight variations for Bach at $\mathrm{v}=7 \mathrm{~m} / \mathrm{s}$ and $\mathrm{v}=8 \mathrm{~m} / \mathrm{s}$ air inlet velocity in the 0.4 TSR zone at $0.17-0.19 \mathrm{CP}$. The Benesh model has higher values for the TSR range $0.5-0.6$ with CP values up to 0.27 . In contrast, the Bach model has the highest power coefficient $(\mathrm{CP})$ value of 0.28 to 0.7 TSR.

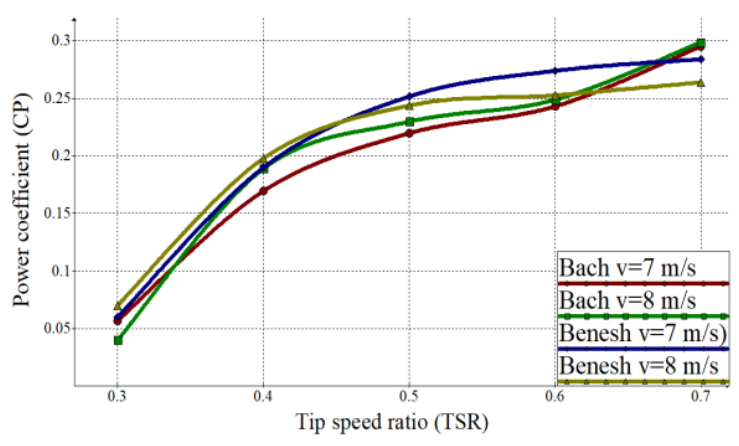

(a) CP for Bach and Benesh

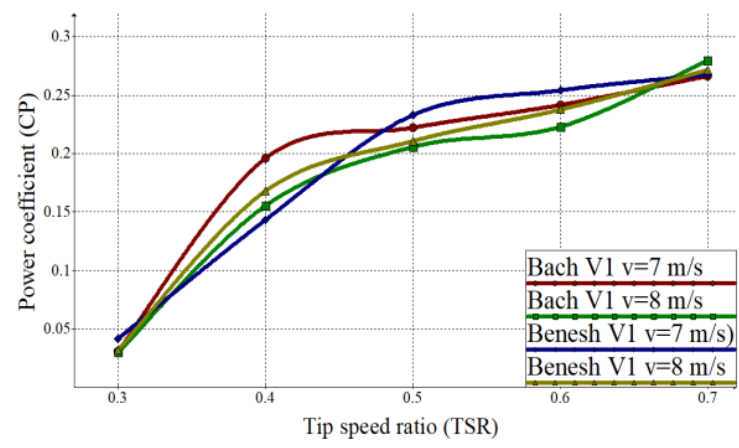

(b) CP for Bach V1 and Benesh V1

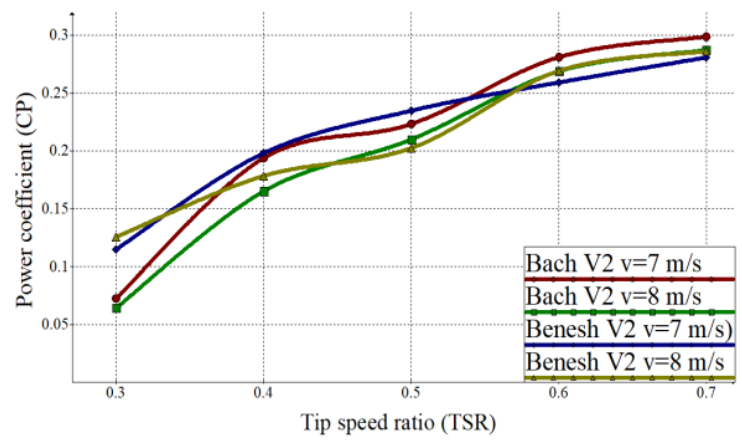

(c) CP for Bach V2 and Benesh V2

Figure 9. Power coefficient (CP) for analyzed rotor models. 


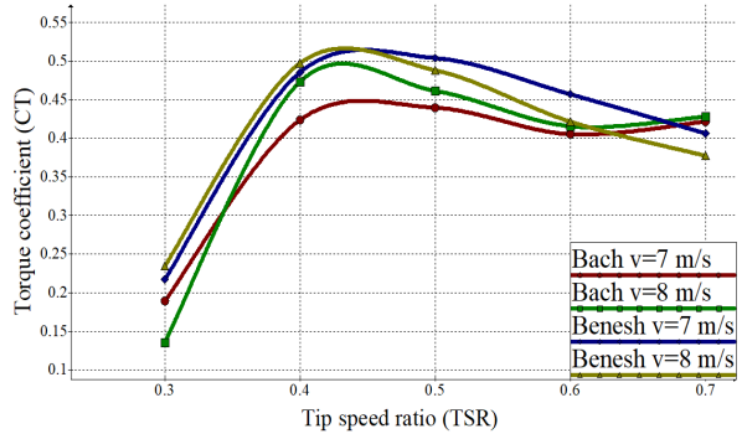

(a) CT for Bach and Benesh

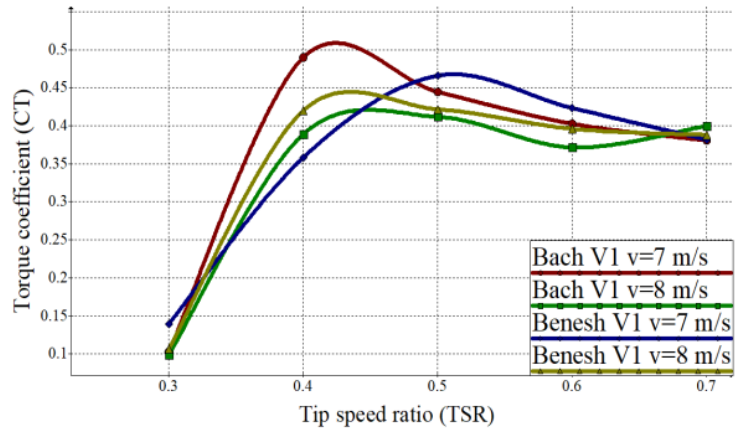

(b) CT for Bach V1 and Benesh V1

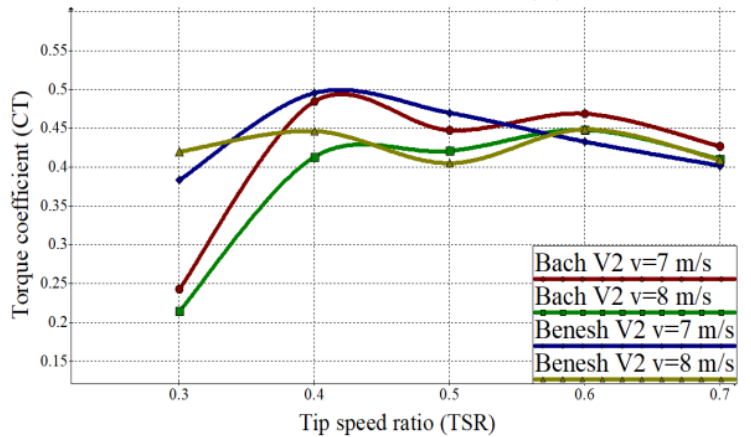

(c) CT for Bach V2 and Benesh V2

Figure 10. Torque coefficient (CT) for analyzed rotor models.

For the constructive variants Bach V1 and Benesh V1, (Figure 9b), higher power coefficient (CP) values of 0.2 for Bach V1 model are registered at 0.4 TSR, but also the lowest value of $0.23 \mathrm{CP}$ at TSR 0.6. For the TSR range between 0.5 and 0.6 the Benesh V1 model has the highest $\mathrm{CP}$ values of 0.23 and 0.25. For TSR 0.7, the Bach V1 model returns with the highest power coefficient (CP) of 0.28.

The constructive variants Bach V2 and Benesh V2 (Figure 9c) show specific values of the power coefficient $(\mathrm{CP})$, starting from the values of $0.3 \mathrm{TSR}$ where power coefficient $(\mathrm{CP})$ of reduced values 0.06-0.07 for Bach V2 and 1.2-1.3 for Benesh V2 are registered. The Benesh V2 model maintains the highest power coefficient $(\mathrm{CP})$ trend for tip speed ratio (TSR) $0.4-0.5$ values with $0.2-0.23 \mathrm{CP}$ values. In contrast, for the end of the analyzed range of tip speed ratio (TSR), the values of the power coefficient $(\mathrm{CP})$ are higher for the Bach V2 model which records values between $0.28-0.3 \mathrm{CP}$.

The torque coefficient (CT) diagrams, presented in Figure 10, show values ranging from 0.1 to $0.52 \mathrm{CT}$ with peak values between 0.4-0.5 TSR for the analyzed rotor models.

For TSR 0.4 Bach V1 presents the highest CT value of 0.5, while Benesh V1 model has lowest CT value of 0.36 (Figure 10b).

The CT values show a progressive decrease tendency over tip speed ratio (TSR) range of 0.5-0.6 with the lowest values recorded by the Bach model from 0.38 CT to 0.6 TSR (Figure 10a).

For the end of the analyzed reference interval of tip speed ratio (TSR) at 0.7 the torque coefficient (CT) values are comparable to the value of $0.4 \mathrm{CT}$.

The Bach V2 and Benesh V2 models (Figure 10c) show considerable value differences of the torque coefficient (CT) for 0.3 TSR. Thus, the Bach V2 model has a lower torque coefficient (CT) for the TSR 0.3 of $0.22-0.29$, while the values for Benesh V2 model are at 0.37-0.42 CT. At TSR 0.4 Bach V2 has values between $0.42-0.48 \mathrm{CT}$, while the Benesh V2 model has values between 0.44-0.49 CT.

By comparing the power coefficient recorded values for Bach, Bach V1 and Bach V2 models (Figure 11a), it can be observed that for TSR 0.3 the lowest values are registered by Bach V1 with $0.03 \mathrm{CP}$. The Bach V2 model has the highest torque coefficient at TSR 0.3 of $0.07 \mathrm{CP}$. At TSR 0.6 the power coefficient $(\mathrm{CP})$ values are between $0.22 \mathrm{CP}$ for the Bach V1 model and $0.28 \mathrm{CP}$ for the Bach V2 model. 
For TSR 0.7 the values are $0.26-0.28 \mathrm{CP}$ for Bach V1, 0.28-0.3 CP for Bach V2 and for Bach model has values between 0.29-0.3.

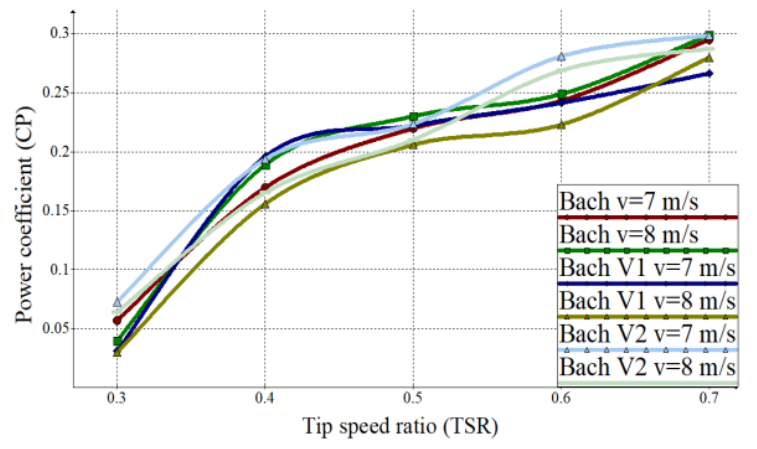

(a) CP for Bach, Bach V1 and Bach V2.

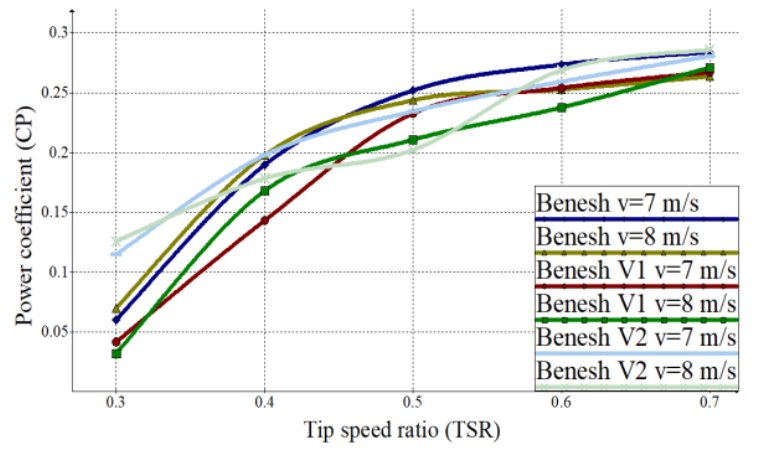

(b) CP for Benesh, Benesh V1, Benesh V2.

Figure 11. Power coefficient (CP) for analyzed rotor models.

The Benesh analyzed models (Figure $11 \mathrm{~b}$ ) presents power coefficient $(\mathrm{CP})$ values of $0.03-0.04$ for Benesh V1 at TSR 0.3, while Benesh V2 has recorded values between 0.12-0.13 CP. At 0.5 TSR the Benesh V2 model has values ranging from $0.2-0.23 \mathrm{CP}$, while the Benesh model has approximate values of 0.25 CP. At 0.6 TSR there are values of $0.24-0.26$ CP of the Benesh V1 model, the Benesh model keeping the growth trend up to $0.25-0.27 \mathrm{CP}$, while the Benesh V2 model has values of $0.26-0.27 \mathrm{CP}$. At 0.7 TSR the Benesh V2 model has values of $0.27-0.29$ CP, while the Benesh V1 model has values of $0.26-0.27 \mathrm{CP}$.

The torque coefficient for the Bach, Bach V1 and Bach V2 analyzed rotor models (Figure 12a) shows specific values according with tip speed ratio (TSR) reference range values. Thus, at 0.3 TSR lower torque values show the Bach V1 model with 0.1 CT. The Bach model has values between 0.3-0.9 CT, while the Bach V2 model has values between 0.21-0.23 CT.

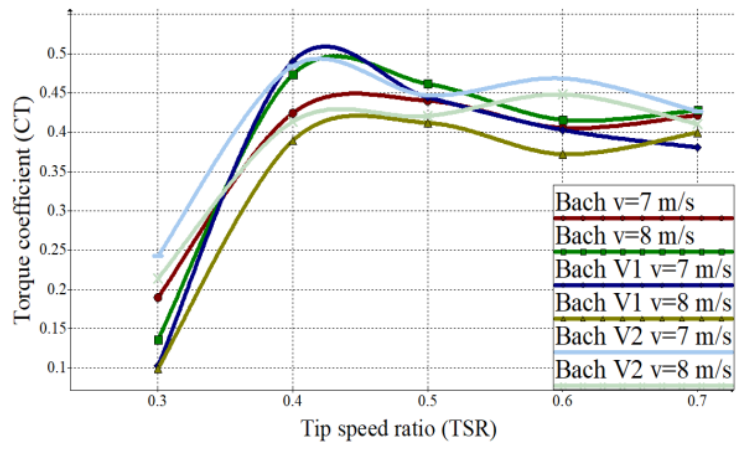

(a) CT for Bach, Bach V1 and Bach V2.

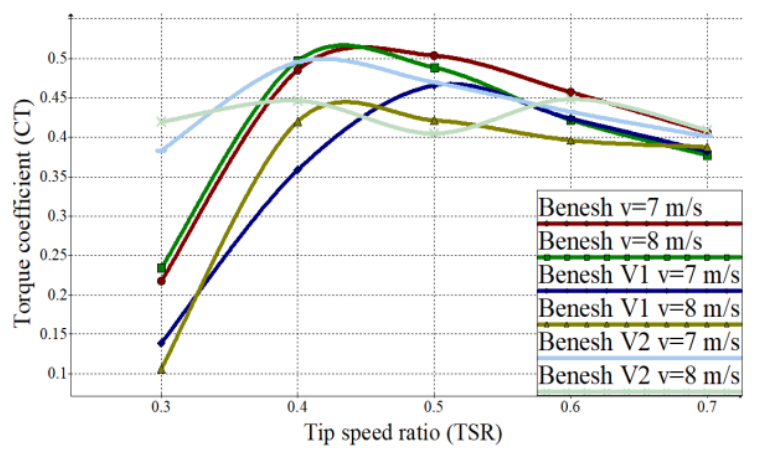

(b) CT for Benesh, Benesh V1 and Benesh V2.

Figure 12. Torque coefficient (CT) for analyzed rotor models.

The highest torque coefficient values are recorded at 0.4 TSR. Bach V1 has values between 0.42-0.48 CT, Bach V1 model has recorded values between 0.39-0.48 and Bach V2 model values between 0.41-0.48. At 0.6 TSR the Bach model has 0.4-0.42 CT, the Bach V1 model has 0.38-0.4 CT and the Bach V2 model has the highest values between 0.46-0.48 CT. At 0.7 TSR the values are concentrated in the range 0.38-0.43 CT with the minimum values for the Bach V1 model and maximum values for the Bach and Bach V2 model.

The CT recorded values for Benesh rotor models (Figure 12b) show non-uniformity at 0.3 TSR. Thus, the lowest values are recorded by Benesh V1 model with values of $0.11-0.14 \mathrm{CT}$. The Benesh model follows with values between $0.22-0.24 \mathrm{CT}$ and the highest torque coefficient values are being recorded by the Benesh V2 model with $0.38-0.42$ CT. At 0.4 TSR the obtained values are $0.35-0.43$ CT for the Benesh V1 model, 0.45-0.5 CT for Benesh V2 model and 0.5 CT for Benesh model. 
At 0.6 TSR the torque coefficient values are between 0.4-0.43 for Benesh V1 model, 0.43-0.46 CT for Benesh model and 0.43-0.45 for Benesh V2 model. At 0.7 TSR the values are more uniform between 0.37-0.41 CT, minimum for Benesh model and maximum values for Benesh V2 model.

\section{Discussion}

For functional constructive optimization of the vertical-axis wind turbine with two-blade rotor model, starting from two constructive models that constituted both numerical and experimental research (Bach and Benesh model) a numerical analysis was performed in order to determine the optimal operating parameters of a rotor model that could be subsequently constructed and analyzed experimentally. Based on the rotor models in different configuration designed and analyzed with Ansys CFX, specific results were obtained which constitute the starting point for establishing the optimal configuration of the rotor model. A comparative analysis based on the obtained results is made in terms of torque and power coefficients.

Air flow analysis on virtual rotor models provides information on air flow velocity rates in the fluid region containing the rotor, as well as specific pressure values.

The numerical results presented in terms of power (CP) (Figure 13a) and torque coefficients (CT) (Figure 13b) are highlighting the functional capacities of each analyzed rotor type, constituting basic information for choosing a certain rotor type in order to be physically constructed depending on certain tip speed ratio (TSR) values at which it will work.

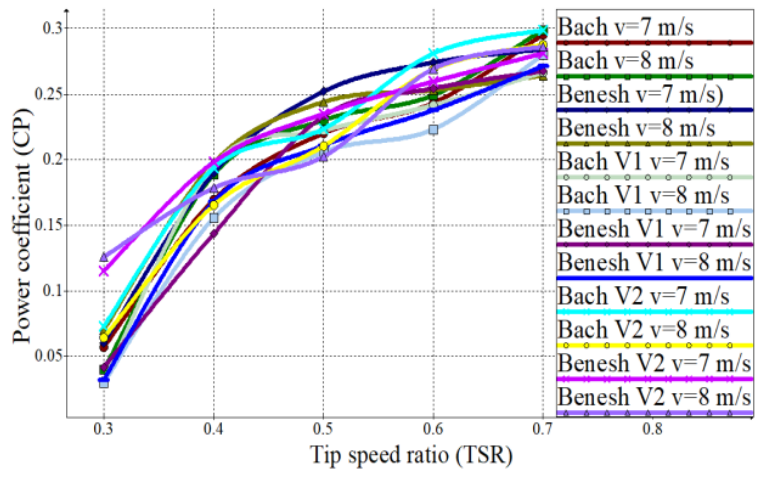

(a) CP for Bach rotor types

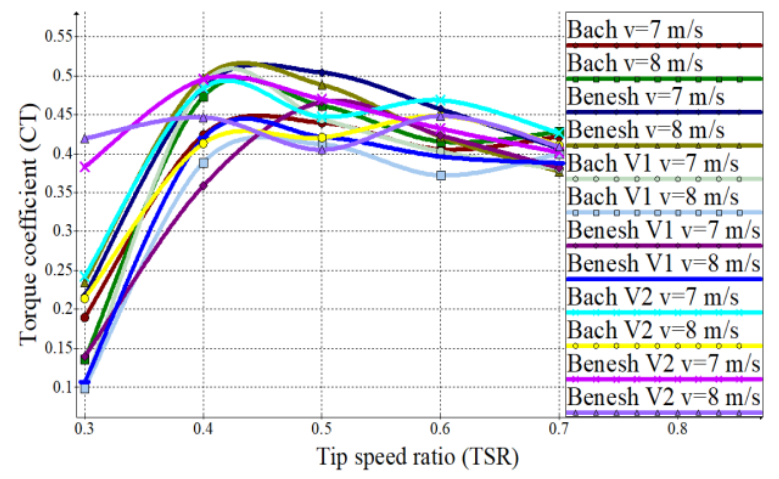

(b) CT for Benesh rotor types

Figure 13. Power and torque coefficients for analyzed rotor models.

Thus, overall, the Bach model presents optimum operating values in terms of torque coefficient (CT) and power (CP) but on certain values of the tip speed ratio (TSR) range also other analyzed rotor models register good results.

At TSR 0.3 the Benesh V2 model offers the highest power coefficient (CP) values of $0.11-0.12$, and the trend is maintained even at TSR 0.4 with $0.2 \mathrm{CP}$ values. In contrast, at TSR 0.5 the Benesh model gives the best result in terms of power coefficient (CP) of 0.25 and at TSR 0.6 values of 0.27 CP. At TSR 0.6 the highest CP values are offered by the Bach V2 model of 0.28 and the lowest value of 0.22 is recorded by the Bach V1. At TSR 0.7 the highest values of the power coefficient (CP) are obtained by the Bach and Bach V2 models, with 0.29-0.3 CP, followed by the Benesh model with 0.26-0.27 CP, as shown in Figure 13a.

The results obtained in terms of torque coefficients (CT) function of tip speed ratio (TSR), values shown (Figure 13b), show the specific values recorded by each analyzed rotor model. Thus, at TSR 0.3 a torque coefficient of $0.38-0.42$ is recorded by the Benesh V2 model being the highest values for this TSR value. The other values are 0.1 CT for Bach V1 and Benesh V1, 0.14-0.18 CT for Bach, 0.22 CT for Bach V2, 0.23 CT for Benesh model, 0.24 for Bach V2. For 0.4 TSR the lowest value of the torque coefficient (CT) is recorded by the Benesh V1 model with $0.36 \mathrm{CT}$, followed by Bach V1 with $0.38 \mathrm{CT}$ 
and Bach model with 0.47. The Benesh V2 model has values between 0.44-0.49 CT. At TSR 0.5 the CT values obtained by Benesh model are in the range $0.4-0.5 \mathrm{CT}$.

At TSR 0.6 the CT values are in the range of $0.37-0.4$ for the Bach V1 model, while the highest values are recorded by the Bach V2 model in the range of $0.45-0.46 \mathrm{CT}$.

For TSR 0.7 there are values between 0.37 recorded by Bach V1 and Benesh rotor models and $0.43 \mathrm{CT}$ for Bach and Bach V2 models. Mean values of the torque coefficient (CT) are recorded by the Benesh model with 0.4 CT.

The obtained values can be constituted as a starting point for establishing and defining the optimal model that can be built on the basis of the above presented results for the purpose of conducting experimental research. The performance characteristics highlighted by the analyzed models in this research stage on virtual rotor models can then be compared and validated with the experimental data obtained from the tests on the experimental model tested in a wind tunnel.

\section{Conclusions}

The Bach and Benesh rotor type models resulted from the structural modification of the Savonius rotor with two blades, are adopted due to the simple design and low production costs and exploitation. These improved models are becoming more interesting for electric energy production based on wind energy conversion. Due to proper constructive-functional optimization methods, are being able to provide good results in electricity production, especially for the case of agricultural farms, residential and commercial installations of reduced size and powers which are positioned far from centralized electrical network grid.

Bach and Benesh rotor model type have been used so far in a small number of practical applications for electricity generation; continuation of studies and experiments for increasing the efficiency in operation of these turbines equipped with these rotors types is of topical importance. Starting from the Bach and Benesh models three-dimensional models with special blade geometry configurations were conceived and analyzed from the point of view of the air flow with certain velocity values through the rotor enclosure.

The obtained results highlight the functional characteristics of each constructive model in terms of torque coefficient $(\mathrm{CT})$ and power $(\mathrm{CP})$.

Overall, the power coefficient offered by the Bach V2 and Benesh V2 rotor models has higher values compared to the classic Bach and Benesh models for the 0.3 TSR of 0.11-012 CP, 0.4 TSR of 0.18 CP (Benesh V2 model) and 0.27 CP at 0.6 TSR (Bach V2). The torque coefficients have comparable values with differences at TSR 0.3 where Benesh V2 models record higher values ranged between $0.38-0.42$ CT.

The obtained results confirm that the modified rotor models obtain higher power coefficients comparative to classical models taken as reference. For the Benesh V2 model the registered CP values are up to $5 \%$ higher at TSR 0.3 compared to the Benesh classical model. The same modified Benesh V2 model offers higher CP power coefficients of $2 \%$ at TSR 0.6 and $3 \%$ at TSR 0.4 compared to the classical Benesh model. Also, Bach V2 modified model offers higher CP values of $4 \%$ compared to the classical Bach model at TSR 0.6.

By means of the presented rotor models and the analyzes performed in this work, essential information gathering was desired regarding the behavior of modified Bach and Benesh turbine rotor variants working at certain wind velocities.

The information is provided by the CFD analysis results performed on the virtual 3D model in terms of $\mathrm{CP}$ and $\mathrm{CT}$ with specific values for each constructive model.

Thus, the efficiency of these constructive types can be evaluated according to the TSR, as well as the establishment of a knowledge base that can be used for future studies.

Future research directions will be directed both to the rotor model optimization and to the construction of the experimental model that will be tested under the wind tunnel conditions in order to identify and validate the optimal results of the numerical analysis on the virtual model. 
Funding: This research received no external funding.

Conflicts of Interest: The authors declare no conflict of interest.

\section{References}

1. Abraham, J.; Plourde, B.D.; Mowry, G.S.; Minkowycz, W.J.; Sparrow, E.M. Summary of Savonius wind turbine development and future applications for small-scale power generation. J. Renew. Sustain. Energy 2012, 4, 42703. [CrossRef]

2. Altan, B.D.; Atılgan, M. An experimental and numerical study on the improvement of the performance of Savonius wind rotor. Energy Convers. Manag. 2008, 49, 3425-3432. [CrossRef]

3. Akwa, J.V.; Vielmo, H.A.; Petry, A.P. A review on the performance of Savonius wind turbines. Renew. Sustain. Energy Rev. 2012, 16, 3054-3064. [CrossRef]

4. Mahmoud, N.; El-Haroun, A.; Wahba, E.; Nasef, M. An experimental study on improvement of Savonius rotor performance. Alex. Eng. J. 2012, 51, 19-25. [CrossRef]

5. Jeon, K.S.; Jeong, J.I.; Pan, J.-K.; Ryu, K.-W. Effects of end plates with various shapes and sizes on helical Savonius wind turbines. Renew. Energy 2015, 79, 167-176. [CrossRef]

6. Kacprzak, K.; Liśkiewicz, G.; Sobczak, K. Numerical investigation of conventional and modified Savonius wind turbines. Renew. Energy 2013, 60, 578-585. [CrossRef]

7. Morshed, K.; Rahman, M.; Molina, G.; Ahmed, M. Wind tunnel testing and numerical simulation on aerodynamic performance of a three-bladed Savonius wind turbine. Int. J. Energy Environ. Eng. 2013, 4, 18. [CrossRef]

8. Sanusi, A.; Soeparman, S.; Wahyudi, S.; Yuliati, L. Experimental study of combined blade savonius wind turbine. Int. J. Renew. Energy Res. 2016, 6, 614-619.

9. Roy, S.; Saha, U.K. Wind tunnel experiments of a newly developed two-bladed Savonius-style wind turbine. Appl. Energy 2015, 137, 117-125. [CrossRef]

10. Ramadan, A.; Yousef, K.; Said, M.; Mohamed, A. Shape optimization and experimental validation of a drag vertical axis wind turbine. Energy 2018, 151, 839-853. [CrossRef]

11. Tian, W.; Song, B.; VanZwieten, J.H.; Pyakurel, P. Computational Fluid Dynamics Prediction of a Modified Savonius Wind Turbine with Novel Blade Shapes. Energies 2015, 8, 7915-7929. [CrossRef]

12. Zhang, B.; Song, B.; Mao, Z.; Tian, W.; Li, B.; Li, B. A Novel Parametric Modeling Method and Optimal Design for Savonius Wind Turbines. Energies 2017, 10, 301. [CrossRef]

13. Zhou, T.; Rempfer, D. Numerical study of detailed flow field and performance of Savonius wind turbines. Renew. Energy 2013, 51, 373-381. [CrossRef]

14. Bach, G. Untersuchungen über Savonius-Rotoren und verwandte Strömungsmaschinen. Forsch. Im Ingenieurwesen 1931, 2, 218-231. [CrossRef]

15. Ushiyama, I.; Nagai, H.; Shinoda, J. Experimentally Determining the Optimum Design Configuration for Savonius Rotors. Bull. JSME 1986, 29, 4130-4138. [CrossRef]

16. Modi, V.J.; Fernando, M.S.U.K. On the Performance of the Savonius Wind Turbine. J. Sol. Energy Eng. 1989, 111, 71-81. [CrossRef]

17. Benesh, A.H. Wind turbine with Savonius-type rotor. U.S. Patent No 5,494,407, 27 February 1996.

18. Sivasegaram, S. An experimental investigation of a class of resistance-type, direction-independent wind turbines. Energy 1978, 3, 23-30. [CrossRef]

19. Chen, L.; Chen, J.; Zhang, Z. Review of the Savonius rotor's blade profile and its performance. J. Renew. Sustain. Energy 2018, 10, 013306. [CrossRef]

20. Rahai, H.R.; Hefazi, H. Development of Optimum Design Configuration and Performance for Vertical Axis Wind turbine; Energy Innovations Small Grant (EISG) Program, Feasibility Analysis Report (FAR), California State University, PIER Subject Area: Renewable Energy Technologies. 2005. Available online: https://www.researchgate.net/publication/228818185_Development_of_Optimum_Design_ Configuration_and_Performance_for_Vertical_Axis_Wind_Turbine (accessed on 20 March 2020).

21. Goanță, A.M. Comparative Study of Advanced Modelling Controls Present in Design Software; The Annals of “Dunarea de Jos" University Of Galati, Fascicle XIV, Mechanichal Engineering; Galati University Press: Galati, Romania, 2012; ISBN 1224-5615. 
22. Ferrari, G.; Federici, D.; Schito, P.; Inzoli, F.; Mereu, R. CFD study of Savonius wind turbine: 3D model validation and parametric analysis. Renew. Energy 2017, 105, 722-734. [CrossRef]

23. Chan, C.M.; Bai, H.; He, D. Blade shape optimization of the Savonius wind turbine using a genetic algorithm. Appl. Energy 2018, 213, 148-157. [CrossRef]

24. Tian, W.; Mao, Z.; Zhang, B.; Li, Y. Shape optimization of a Savonius wind rotor with different convex and concave sides. Renew. Energy 2018, 117, 287-299. [CrossRef]

25. Wenehenubun, F.; Saputra, A.; Sutanto, H. An Experimental Study on the Performance of Savonius Wind Turbines Related with the Number of Blades. Energy Procedia 2015, 68, 297-304. [CrossRef]

26. Alaimo, A.; Esposito, A.; Milazzo, A.; Orlando, C.; Trentacosti, F. Slotted Blades Savonius Wind Turbine Analysis by CFD. Energies 2013, 6, 6335-6351. [CrossRef]

27. Roy, S.; Saha, U.K. Review on the numerical investigations into the design and development of Savonius wind rotors. Renew. Sustain. Energy Rev. 2013, 24, 73-83. [CrossRef]

28. Afungchui, D.; Kamoun, B.; Helali, A. Vortical structures in the wake of the savonius wind turbine by the discrete vortex method. Renew. Energy 2014, 69, 174-179. [CrossRef]

29. Shaheen, M.; El-Sayed, M.; Abdallah, S. Numerical study of two-bucket Savonius wind turbine cluster. J. Wind. Eng. Ind. Aerodyn. 2015, 137, 78-89. [CrossRef]

30. Zemamou, M.; Aggour, M.; Toumi, A. Review of savonius wind turbine design and performance. Energy Procedia 2017, 141, 383-388. [CrossRef]

31. Kang, C.; Liu, H.; Yang, X. Review of fluid dynamics aspects of Savonius-rotor-based vertical-axis wind rotors. Renew. Sustain. Energy Rev. 2014, 33, 499-508. [CrossRef]

32. Al-Faruk, A.; Sharifian, A. Flow Field and Performance Study of Vertical Axis Savonius Type SST Wind Turbine. Energy Procedia 2017, 110, 235-242. [CrossRef]

33. Olaoye, O.S.; Adeoye, O. Numerical Investigation and Improvement of AerodynamicPerformance of Savonius Wind Turbine. J. Energy Technol. Policy 2016, 6, 6.

34. García, A.A.; Gutiérrez-Torres, C.; Jiménez-Bernal, J.A. Computational Fluid Dynamics in Turbulent Flow Applications, Numerical Simulation-From Brain Imaging to Turbulent Flows. Available online: https:/www.intechopen.com/books/numerical-simulation-from-brain-imaging-to-turbulent-flows/ computational-fluid-dynamics-in-turbulent-flow-applications (accessed on 20 March 2020).

35. Scurtu, I.C.; Panaitescu, V.N. Turbulent Flow Numerical Simulation for Unconventional Propulsion. Rev. Chim. 2019, 70, 3508-3511. [CrossRef]

36. Boşneagu, R.; Scurtu, I.C.; Mateescu, R.-D.; Dumitrache, L.; Mihailov, M.-E.; Popov, P. Simulation on marine currents at Midia Cape-Constanta area using computational fluid dynamics method. Therm. Sci. 2018, 22, 353-360. [CrossRef]

(C) 2020 by the author. Licensee MDPI, Basel, Switzerland. This article is an open access article distributed under the terms and conditions of the Creative Commons Attribution (CC BY) license (http://creativecommons.org/licenses/by/4.0/). 